\title{
Simplified Passive Earth Pressure Element
}

\section{Suchart Limkatanyu*, Minho Kwon**, and Wooyoung Jung***}

\section{Erratum to: KSCE Journal of Civil Engineering (2014) 18(5):1359-1363 \\ DOI 10.1007/s12205-014-0138-6}

This original article unfortunately contained the typos due to the problem of publishing system.

\section{Errata:}

1. $\mathbf{G}_{R B M}$ in Eqs. (4), (5)

Should be corrected to:

$$
\Gamma_{R B M}
$$

2. $\mathbf{Y}[\mathrm{d}]$ in Eq. (6)

Should be corrected to:

$$
\Psi[\mathrm{d}]
$$

3. Equilibrium relation between the contact-interface force $\mathbf{D}$ and the element nodal forces $\mathbf{P}$ can be obtained using the invariant property of virtual work. Substituting Eq. (4), and subsequently imposing the arbitrariness of the virtual nodal displacements $d \mathbf{U}$ result in the following equilibrium relation:

$$
\mathbf{G}_{R B M}^{T} \mathbf{D}=\mathbf{P}
$$

Substitution of Eqs. (7) into (8) yields the incremental form of equilibrium as:

$$
\mathbf{K} \Delta \mathbf{U}=\mathbf{P}-\mathbf{P}^{0}
$$

where, $\mathbf{K}=\mathbf{G}_{R B M}^{T} \mathbf{k} \mathbf{G}_{R B M}$ is the passive-earth pressure element stiffness matrix; and $\mathbf{P}^{0}=\mathbf{G}_{R B M}^{T} \mathbf{D}^{0}$ is the element resistant force vector.

Should be corrected to:

Equilibrium relation between the contact-interface force $\mathbf{D}$ and the element nodal forces $\mathbf{P}$ can be obtained using the invariant property of virtual work. Substituting Eq. (4), and subsequently imposing the arbitrariness of the virtual nodal displacements $\delta \mathbf{U}$ result in the following equilibrium relation:

$$
\Gamma_{R B M}^{T} \mathbf{D}=\mathbf{P}
$$

*Associate Professor, Dept. of Civil Engineering, Faculty of Engineering, Prince of Songkla University, Songkhla, Thailand (E-mail: suchart.1@psu.ac.th) **Member, Professor, Dept. of Civil Engineering, ERI, Gyeongsang National University, Jinju 660-701, Korea (Corresponding Author, E-mail: kwonm@gnu.ac.kr)

***Member, Associate Professor, Dept. of Civil Engineering, Gangneung-Wonju National University, Gangneung 210-702, Korea (E-mail: woojung@gwnu.ac.kr) 
Substitution of Eqs. (7) into (8) yields the incremental form of equilibrium as:

$\mathbf{K} \Delta \mathbf{U}=\mathbf{P}-\mathbf{P}^{0}$

where, $\mathbf{K}=\boldsymbol{\Gamma}_{R B M}^{T} \mathbf{k} \Gamma_{R B M}$ is the passive-earth pressure element stiffness matrix; and $\mathbf{P}^{0}=\Gamma_{R B M}^{T} \mathbf{D}^{0}$ is the element resistant force vector.

4. As reported in Rollins and Cole (2006), the geotechnical properties of the silty sand backfill are: soil cohesion $c=27.3 \mathrm{kPa}$; moist unit weight $g_{m}=18.99 \mathrm{kM} / \mathrm{m}^{3}$; friction angle $f=27^{\circ}$; relative density $D_{r}=67 \%$; and interface friction angle $d=20^{\circ}$.

Should be corrected to:

As reported in Rollins and Cole (2006), the geotechnical properties of the silty sand backfill are: soil cohesion $c=27.3 \mathrm{kPa}$; moist unit weight $\gamma_{m}=18.99 \mathrm{kN} / \mathrm{m}^{3}$; friction angle $\phi=27^{\circ}$; relative density $D_{r}=67 \%$; and interface friction angle $\delta=20^{\circ}$.

\section{Refrerences}

Should be corrected to:

References 